\title{
Leptin and Leptin Receptor Expression in Breast Cancer
}

Hee Sung Kim, M.D., Ph.D.

Department of Pathology, Kangbuk Samsung Hospital, Sungkyunkwan University School of Medicine, Seoul, Korea

\section{Purpose}

Leptin is a multifunctional hormone that's produced by adipose tissue and leptin is involved in the regulation of food intake and energy balance. The aims of this study were to determine the leptin and leptin receptor (Ob-R) expressions in human breast cancer and their corresponding influence on the prognosis of patients with breast cancer.

\section{Materials and Methods}

We examined the correlations between the leptin and $\mathrm{Ob}-\mathrm{R}$ expressions and the breast cancer-related pathobiologic markers by performing immunohistochemistry in 517 patients with breast cancer. We analyzed the leptin and $\mathrm{Ob}-\mathrm{R}$ expressions with respect to overall survival and relapse-free survival (RFS).

\section{Results}

Positive cytoplasmic immunoreactivity for leptin was noted in $39 \%$ of the patients and $79 \%$ of the patients showed positive cytoplasmic immunoreactivity for $\mathrm{Ob}-\mathrm{R}$. The expression of leptin in breast cancer was correlated with a high Ki-67 labeling index $(p=0.019)$. Based on the univariate survival analysis, the clinicopathologic variables with prognostic value included the histologic grade, the T stage, the N stage, the HER2 status, the Bcl-2, p53 and Ki-67 expressions $(p<0.05)$. The patients with leptin-positive breast cancers and a negative hormone receptor status had a significantly longer overall survival $(p=0.021)$. Multivariate survival analysis showed that a positive expression of leptin was an independent prognostic marker for overall survival (hazard ratio, $0.20 ; 95 \% \mathrm{Cl}, 0.04 \sim 0.99 ; \mathrm{p}=0.05$ ).

\section{Conclusion}

A leptin expression in breast cancer is significantly associated with the Ki-67 labeling index, and this suggests there is an association of a leptin expression with the proliferation activity. In addition, a leptin expression is an indicator of better survival for breast cancer patients.

\section{Key words}

Breast neoplasms, Leptin, Leptin receptor, Survival

\section{Introduction}

Obesity is an important and manageable risk factor for the development and progression of postmenopausal breast cancer (1). There is evidence suggesting that the increased production and secretion of adipocyte-derived growth factors and hormones contribute to cellular transformation and tumorigenesis $(2,3)$. Leptin is required for the breast's normal mammary gland development and lactation, but leptin might also contribute to mammary tumorigenesis (4). It has been previously shown that leptin and leptin receptor (Ob$\mathrm{R}$ ) are overexpressed in primary and metastatic invasive ductal breast carcinoma as compared to that of healthy mammary tissues (5).

Leptin is a product of the obese $(o b)$ gene, and leptin is an adipocytokine that regulates appetite, bone formation, reproduction, cellular proliferation and angiogenesis (6). Several actions of leptin, including the stimulation of normal and tumorous cell growth, migration, invasion and enhancement of angiogenesis, suggest that this hormone can promote an aggressive breast cancer phenotype that is estrogen-independent (7).

In vitro studies have demonstrated that leptin stimulates the growth, survival and transformation of breast cancer cells (4), and it does so primarily by activating the Janus kinase/signal transducers and activators of transcription (JAK/STAT) signaling pathway $(8,9)$ 
and the phosphoinositol-3-kinase (PI3K)/protein kinase B (Akt) and mitogen-activated protein kinase (MAPK) pathways (10).

We studied the correlations between the immunohistochemical expression of leptin/Ob-R and the breast cancer-related prognostic variables, and we analyzed their correlations with overall survival and relapse-free survival (RFS) in 517 patients with breast cancer.

\section{Materials and Methods}

\section{Patients}

Five hundred seventeen patients (median age: 46 years, age range: $23 \sim 84$ years) with breast carcinomas were included in this study. The patients underwent breast cancer surgery at the National Cancer Center (Goyang, Korea) and at Kangbuk Samsung Hospital (Seoul, Korea) between 2000 and 2006. Three hundred fifty-two of the patients with breast cancer underwent survival analysis. The mean follow-up was 53 months (range: $7 \sim 85$ months). The immunohistochemical expression of leptin/Ob-R was analyzed in the 517 patients with breast cancer. The RFS was calculated as the period from surgery until the date of the first tumor recurrence. This study was submitted to and met the guidelines of the local institutional review committees.

A standard histopathologic examination was done that included determining the type of cancer and the pathologic tumor stage, which were assessed according to the criteria established by the $6^{\text {th }}$ edition AJCC staging manual (11). Forty-six of the 517 patients (9\%) had in situ carcinoma. The histologic types of invasive cancers were mucinous carcinoma $(n=8)$, medullary carcinoma $(n=3)$, metaplastic carcinoma $(\mathrm{n}=1)$, tubulolobular carcinoma $(\mathrm{n}=1)$, lobular carcinoma $(n=1)$ and ductal not otherwise specified (NOS; $n=457)$.

\section{H\&E and immunohistochemical staining}

All of the tissues obtained from the patients were routinely fixed in $10 \%$ buffered formalin and then they were embedded in paraffin blocks. The tissue array blocks containing the breast cancer tissues (tissue cores $6 \mathrm{~mm}$ in diameter) were produced from the enrolled cases. The tissue microarray blocks were sectioned at a $4-\mu \mathrm{m}$ thickness and these were processed for immunohistochemical staining. The paraffin was removed from the tissue sections with xylene. The sections were rehydrated in a graded series of ethanol solutions and then the sections were immersed in Tris-buffered saline. The expressions of leptin and Ob-R were investigated by immunohistochemical staining with using rabbit polyclonal antibodies against leptin (A20, 1:00 dilution; Santa Cruz Biotechnology, Inc., Santa Cruz, CA) and goat polyclonal antibodies against Ob-R (M-18, $1: 30$ dilution; Santa Cruz
Biotechnology). A biotinylated anti-mouse antibody was used as a secondary antibody, and streptavidin horseradish peroxidase (Zymed Laboratories, San Francisco, CA) was used following the instructions provided by the manufacturer. The sections were counterstained in Mayer's hematoxylin; they were then dehydrated and cleared, and the sections were mounted for examination.

\section{Interpretation of the immunohistochemistry findings}

The immunohistochemical expression was evaluated as the percentage of the cells that had cytoplasmic staining for leptin and membranous staining for $\mathrm{Ob}-\mathrm{R}$ with any intensity. The expression was scored as positive if $>5 \%$ of the cells were reactive with any intensity (4).

A cutoff value of $10 \%$ for the positively stained nuclei was used to define positivity for estrogen receptor (ER) and progesterone receptor (PR). Cytoplasmic staining with any intensity in $>10 \%$ of the tumor cells was scored as positive for Bcl-2. Membranous staining for HER2 was scored as follows: 0, no staining or membranous staining in $<10 \%$ of the cells; $1+$, faint incomplete staining in $10 \%$ of the cells; $2+$, weak-to-moderate complete staining in $10 \%$ of the cells; and $3+$, strong complete staining in 1 $0 \%$ of the cells. An HER 2 overexpression was defined as a score of $3+$. The cells that stained for Ki-67 and p53 were expressed as a percentage. The Ki-67 labeling index was graded as low if the number of positive cells was $<10 \%$ and high if the number of positive cells was $\geq 10 \%$. The staining for $\mathrm{p} 53$ was scored as positive if $>10 \%$ of the cells were positive with a strong intensity.

\section{$4 \overline{\text { Statistical analysis }}$}

Statistical analysis was performed with using SPSS software, version 15.0 (SPSS, Inc., Chicago, IL). Pearson's $x^{2}$ test was used to examine the correlation between the variables. The Kaplan-Meier curves were plotted from the data of the overall survival and the RFS. We estimated the hazard ratios along with the $95 \%$ CIs for assessing the association of the leptin expression and the $\mathrm{Ob}-\mathrm{R}$ expression with overall survival and RFS by using the Cox proportional hazards model, with adjustment for the tumor size $(\leq 2$ $\mathrm{cm}$ or $>2 \mathrm{~cm}$ ), the nodal status (negative or positive), the hormone receptor status (negative or positive), chemotherapy (yes or no) and hormone therapy (yes or no). A p-value $<0.05$ was considered to be statistically significant. 
Table 1. Characteristics of the study population

\begin{tabular}{|c|c|c|c|}
\hline Variables & & No $(\mathrm{n}=517)$ & $\%$ \\
\hline \multirow[t]{2}{*}{ Age } & $<50$ & 317 & 61 \\
\hline & $\geq 50$ & 200 & 39 \\
\hline \multirow[t]{2}{*}{ BMI* } & $<25$ & 176 & 74 \\
\hline & $\geq 25$ & 63 & 26 \\
\hline \multirow[t]{3}{*}{ Histologic grade } & G1 & 106 & 24 \\
\hline & G2 & 178 & 40 \\
\hline & G3 & 159 & 36 \\
\hline \multirow[t]{5}{*}{ T stage } & $\mathrm{T} 0$ & 46 & 9 \\
\hline & $\mathrm{T} 1$ & 234 & 46 \\
\hline & $\mathrm{T} 2$ & 199 & 39 \\
\hline & $\mathrm{T} 3$ & 29 & 6 \\
\hline & $\mathrm{T} 4$ & 4 & 1 \\
\hline \multirow[t]{4}{*}{$\mathrm{N}$ stage } & N0 & 325 & 63 \\
\hline & N1 & 109 & 21 \\
\hline & $\mathrm{N} 2$ & 38 & 7 \\
\hline & N3 & 45 & 9 \\
\hline \multirow[t]{5}{*}{ AJCC staging } & 0 & 46 & 9 \\
\hline & I & 170 & 33 \\
\hline & II & 204 & 40 \\
\hline & III & 91 & 18 \\
\hline & IV & 1 & 0 \\
\hline \multirow[t]{2}{*}{ Hormone receptor } & Negative & 183 & 36 \\
\hline & Positive & 326 & 64 \\
\hline \multirow[t]{2}{*}{ HER2 } & No overexpression & 413 & 81 \\
\hline & Overexpression & 97 & 19 \\
\hline \multirow[t]{4}{*}{ Intrinsic type } & Luminal A & 297 & 58 \\
\hline & Luminal B & 29 & 6 \\
\hline & HER2 overexpressing & 68 & 13 \\
\hline & Triple negative & 115 & 23 \\
\hline \multirow[t]{4}{*}{ Systemic therapy after surgery } & Chemotherapy only & 81 & 23 \\
\hline & Chemotherapy and hormone therapy & 189 & 54 \\
\hline & Hormone therapy only & 64 & 18 \\
\hline & None & 18 & 5 \\
\hline
\end{tabular}

*body mass index.

\section{Results}

\section{Clinicopathologic correlation of the leptin expression and the Ob-R expression in the breast cancer tissues}

The clinicopathologic characteristics of the enrolled patients are shown in Table 1. Positive cytoplasmic immunoreactivity for leptin was found in 39\% of the cases (190 of 490). Positive cytomembranous staining for Ob-R was noted in 78\% of the cases (369 of 473; Fig. 1, Table 2).

Neither the leptin expression nor the Ob-R expression had a significant correlation with age, the BMI, the histologic grade, the $\mathrm{T}$ stage, the $\mathrm{N}$ stage or the AJCC staging. The expression of leptin in breast cancer was correlated with a high Ki-67 labeling index $(\mathrm{p}=0.019)$. The rate of the leptin expression was significantly higher for the breast cancers of the triple negative $(\mathrm{TN})$ type than that for the non-TN type $(\mathrm{p}=0.022)$. Although there was no statistical significance, the rate of a leptin expression was higher for the breast cancers that had no expression of hormone receptors $(\mathrm{p}=0.08)$, no $\mathrm{p} 53$ overexpression $(\mathrm{p}=0.08)$ and no bcl- 2 expression $(\mathrm{p}=0.38)$. The rate of an Ob-R expression was higher for the non-TN breast cancers $(\mathrm{p}=0.045)$ and the breast cancers with a high Ki-67 labeling index $(\mathrm{p}=0.06$; Table 2$)$.

We categorized the leptin/Ob-R expression into leptin $+/ \mathrm{Ob}-\mathrm{R}+$, leptin+/Ob-R-, leptin-/Ob-R+ and leptin-/Ob-R-. The leptin+/Ob$\mathrm{R}+$ breast cancers showed a tendency to have a higher Ki-67 labeling index than did the other groups ( $\mathrm{p}=0.014$; Table 3 ). 


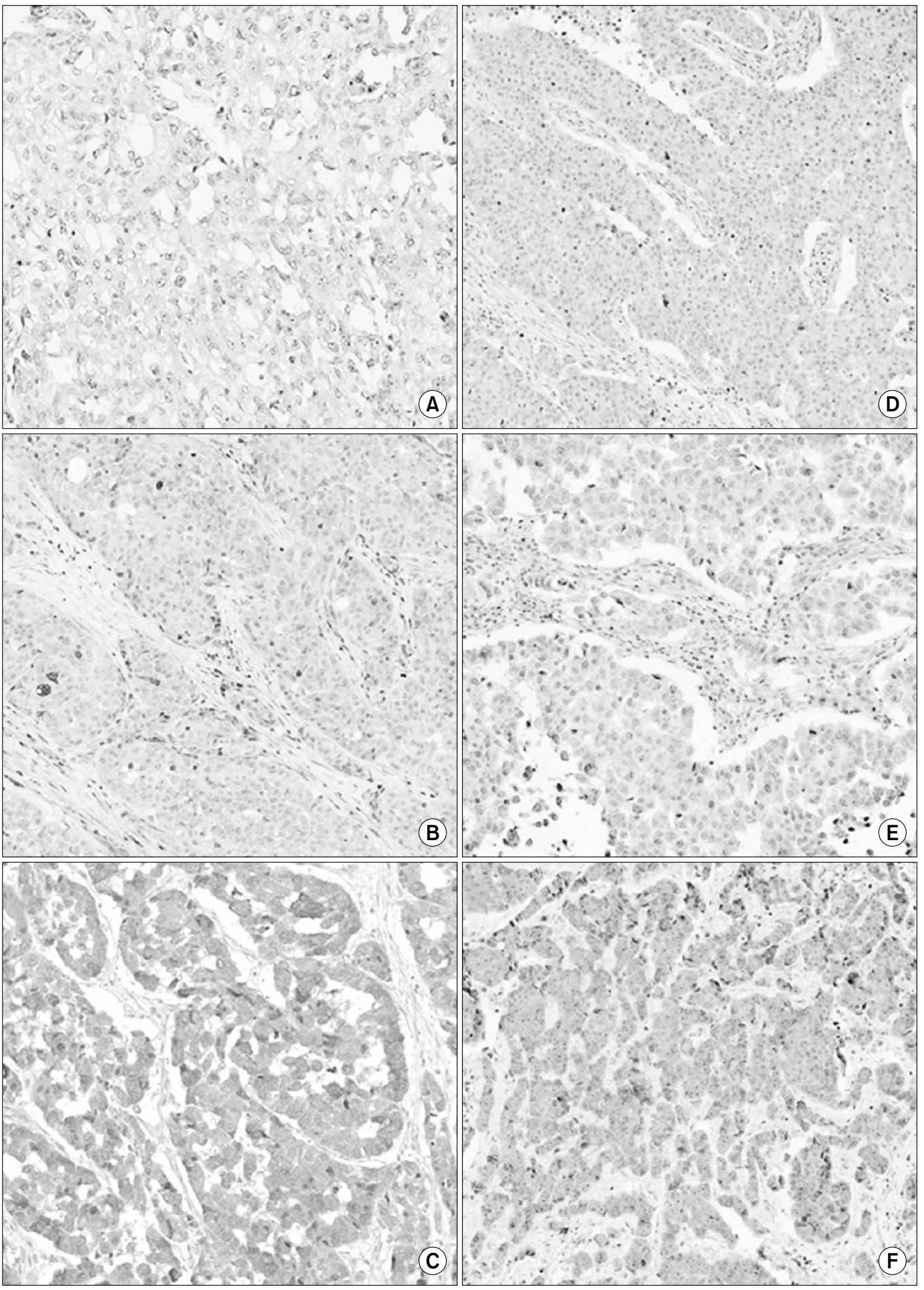

Fig. 1. Immunohistochemical detection of a leptin expression and an $\mathrm{Ob}-\mathrm{R}$ expression in breast cancer tissues. (A $\sim \mathrm{C}$ for leptin.) (A) is negative, (B) is weak positive and (C) is strong positive. (D F for Ob-R.) (D) is negative, (E) is weak positive and (F) is strong positive. 
Table 2. Clinicopathologic characteristics related to leptin and Ob-R expression in breast cancer tissues

\begin{tabular}{|c|c|c|c|c|c|c|c|c|c|c|c|}
\hline \multirow{2}{*}{ Variables } & & \multicolumn{2}{|c|}{ Leptin-negative } & \multicolumn{2}{|c|}{ Leptin-positive } & \multirow{2}{*}{$\mathrm{p}$} & \multicolumn{2}{|c|}{ Ob-R-negative } & \multicolumn{2}{|c|}{ Ob-R-positive } & \multirow{2}{*}{$\mathrm{p}$} \\
\hline & & No & $\%$ & No & $\%$ & & No & $\%$ & No & $\%$ & \\
\hline \multirow[t]{2}{*}{ Age } & $<50$ & 175 & 59 & 122 & 41 & 0.19 & 66 & 23 & 223 & 77 & 0.58 \\
\hline & $\geq 50$ & 125 & 65 & 68 & 35 & & 38 & 21 & 146 & 79 & \\
\hline \multirow[t]{2}{*}{ BMI } & $<25$ & 101 & 57 & 75 & 43 & 0.40 & 45 & 26 & 125 & 74 & 0.06 \\
\hline & $\geq 25$ & 40 & 63 & 23 & 37 & & 9 & 15 & 52 & 85 & \\
\hline \multirow[t]{2}{*}{ Histologic grade } & $\mathrm{G} 1 / 2$ & 177 & 65 & 96 & 35 & 0.11 & 63 & 24 & 196 & 76 & 0.67 \\
\hline & G3 & 83 & 55 & 69 & 45 & & 32 & 22 & 116 & 78 & \\
\hline \multirow[t]{2}{*}{ T stage } & $\mathrm{T} \leq 1$ & 160 & 62 & 99 & 38 & 0.90 & 50 & 20 & 202 & 80 & 0.35 \\
\hline & $\mathrm{T} \geq 2$ & 121 & 62 & 73 & 38 & & 44 & 24 & 143 & 76 & \\
\hline \multirow[t]{2}{*}{ N stage } & N0 & 190 & 63 & 114 & 37 & 0.34 & 62 & 21 & 229 & 79 & 0.98 \\
\hline & $\mathrm{N} \geq 1$ & 82 & 58 & 60 & 42 & & 30 & 21 & 110 & 79 & \\
\hline \multirow[t]{2}{*}{ AJCC staging } & Early $[\leq \mathrm{IIB}]$ & 202 & 60 & 134 & 40 & 0.49 & 68 & 21 & 258 & 79 & 0.36 \\
\hline & Advanced [ $\geq$ IIIA] & 97 & 63 & 56 & 37 & & 36 & 25 & 110 & 75 & \\
\hline \multirow[t]{2}{*}{ Hormone receptor } & Negative & 99 & 56 & 78 & 44 & 0.08 & 43 & 26 & 125 & 74 & 0.15 \\
\hline & Positive & 199 & 64 & 112 & 36 & & 60 & 20 & 242 & 80 & \\
\hline \multirow[t]{2}{*}{ HER2 } & No overexpression & 238 & 60 & 159 & 40 & 0.29 & 85 & 22 & 295 & 78 & 0.59 \\
\hline & Overexpression & 60 & 66 & 31 & 34 & & 18 & 20 & 73 & 80 & \\
\hline \multirow[t]{2}{*}{ Intrinsic type } & Triple negative & 58 & 52 & 54 & 48 & 0.02 & 30 & 29 & 73 & 71 & 0.05 \\
\hline & Non-triple negative & 240 & 64 & 136 & 36 & & 73 & 20 & 294 & 80 & \\
\hline \multirow[t]{2}{*}{ Bcl-2 expression } & Negative & 114 & 58 & 82 & 42 & 0.38 & 44 & 24 & 142 & 76 & 0.31 \\
\hline & Positive & 174 & 62 & 106 & 38 & & 54 & 20 & 220 & 80 & \\
\hline \multirow[t]{2}{*}{ p53 expression } & Negative & 226 & 64 & 129 & 36 & 0.08 & 72 & 21 & 274 & 79 & 0.77 \\
\hline & Positive & 65 & 55 & 54 & 45 & & 25 & 22 & 88 & 78 & \\
\hline \multirow[t]{2}{*}{ Ki-67 labeling index } & Low $[<10 \%]$ & 209 & 64 & 119 & 36 & 0.02 & 73 & 23 & 247 & 77 & 0.06 \\
\hline & High $[\geq 10 \%]$ & 64 & 52 & 60 & 48 & & 18 & 15 & 104 & 85 & \\
\hline \multirow[t]{2}{*}{ Leptin expression } & Negative & 300 & 100 & 0 & 0 & & 64 & 22 & 221 & 78 & 0.57 \\
\hline & Positive & 0 & 0 & 190 & 100 & & 36 & 20 & 142 & 80 & \\
\hline \multirow[t]{2}{*}{ Ob-R expression } & Negative & 64 & 64 & 36 & 36 & 0.57 & 104 & 100 & 0 & 0 & \\
\hline & Positive & 221 & 61 & 142 & 39 & & 0 & 0 & 369 & 100 & \\
\hline
\end{tabular}

Table 3. Correlation for expression of leptin/Ob-R and Ki-67 labeling index in breast cancers

\begin{tabular}{|c|c|c|c|c|c|c|c|}
\hline \multirow{2}{*}{ Recombination } & \multicolumn{2}{|c|}{ Total $(n=463)$} & \multicolumn{2}{|c|}{ Low Ki-67 $(<10 \%)$} & \multicolumn{2}{|c|}{ High Ki-67 ( $\geq 10 \%)$} & \multirow{2}{*}{$\mathrm{p}$} \\
\hline & No & $\%$ & No & $\%$ & No & $\%$ & \\
\hline Leptin $+/ \mathrm{Ob}-\mathrm{R}+$ & 142 & 31 & 87 & 64 & 50 & 37 & 0.01 \\
\hline Leptin $+/ \mathrm{Ob}-\mathrm{R}-$ & 36 & 7 & 24 & 73 & 9 & 27 & \\
\hline Leptin-/Ob-R+ & 221 & 48 & 157 & 75 & 52 & 25 & \\
\hline Leptin-/Ob-R_- & 64 & 14 & 46 & 85 & 8 & 15 & \\
\hline
\end{tabular}

\section{Survival analysis for the leptin expression and the Ob-R expression in the breast cancer patients}

Based on the univariate Kaplan-Meier analysis of all 352 cases for the overall survival, the clinicopathologic variables with prognostic value included the histologic grade, the $\mathrm{T}$ stage, the $\mathrm{N}$ stage, the HER2 status and a Ki-67 expression $(\mathrm{p}<0.05$; Table 4$)$. No significant difference in overall survival was noted between the leptin-negative and leptin-positive groups or the Ob-R-negative and
Ob-R-positive groups. Based on a stratified analysis by the hormone receptor status, the patients who had breast cancer with a negative hormone receptor status and a leptin expression had a longer overall survival than the patients who had breast cancer with a negative hormone receptor and no leptin expression (Fig. 2B, Table 5). Based on the univariate Kaplan-Meier analysis of all 352 cases for RFS, the clinicopathologic variables with prognostic value included the $T$ stage, the $\mathrm{N}$ stage, the HER2 status and a p53 expression ( $<<0.05$; Table 4). On multivariate survival analysis, tumor size, the lymph 
Cancer Res Treat. 2009;41(3):155-163

Table 4. Univariate survival analysis of prognostic factors for overall survival and relapse-free survival (RFS)

\begin{tabular}{|c|c|c|c|c|c|c|}
\hline Characteristics & Group & $\mathrm{N}(\%)$ & Overall survival (\%) & p-value & RFS (\%) & p-value \\
\hline \multirow[t]{2}{*}{ Age } & $<50$ & $224(64)$ & 91.9 & 0.65 & 82.6 & 0.04 \\
\hline & $\geq 50$ & $128(36)$ & 93.8 & & 86.7 & \\
\hline \multirow[t]{2}{*}{ Histologic grade } & $\mathrm{G} 1 / 2$ & $194(63)$ & 94.8 & 0.01 & 85.1 & 0.23 \\
\hline & G3 & $115(37)$ & 86.1 & & 80.9 & \\
\hline \multirow{2}{*}{$\mathrm{T}$ stage } & $\mathrm{T} \leq 1$ & $191(58)$ & 97.4 & 0.01 & 91.7 & 0.04 \\
\hline & $\mathrm{T} \geq 2$ & $138(42)$ & 90.5 & & 83.5 & \\
\hline \multirow[t]{2}{*}{$\mathrm{N}$ stage } & N0 & $218(68)$ & 97.2 & 0.05 & 92.2 & 0.00 \\
\hline & $\mathrm{N} \geq 1$ & $104(32)$ & 92.3 & & 79.8 & \\
\hline \multirow[t]{2}{*}{ BMI* } & $<25$ & $142(10)$ & 99.3 & 0.00 & 93.0 & 0.00 \\
\hline & $\geq 25$ & $47(5)$ & 97.8 & & 89.4 & \\
\hline \multirow[t]{2}{*}{ Hormone receptor } & Negative & $131(37)$ & 86.2 & 0.00 & 79.4 & 0.04 \\
\hline & Positive & $220(63)$ & 96.4 & & 86.8 & \\
\hline \multirow[t]{2}{*}{ HER2 } & No overexpression & $281(80)$ & 95.0 & 0.00 & 87.5 & 0.00 \\
\hline & Overexpression & $70(20)$ & 82.6 & & 70.0 & \\
\hline \multirow[t]{2}{*}{ Ki-67 labeling index } & Low & $242(73)$ & 95.0 & 0.01 & 83.9 & 0.89 \\
\hline & High & $89(27)$ & 84.3 & & 84.3 & \\
\hline \multirow[t]{2}{*}{ Leptin expression } & Negative & $201(60)$ & 90.0 & 0.10 & 83.1 & 0.78 \\
\hline & Positive & $136(40)$ & 95.6 & & 84.6 & \\
\hline \multirow[t]{2}{*}{ Ob-R expression } & Negative & $84(26)$ & 91.6 & 0.84 & 84.5 & 0.85 \\
\hline & Positive & $244(74)$ & 92.6 & & 83.2 & \\
\hline
\end{tabular}

*body mass index.

A

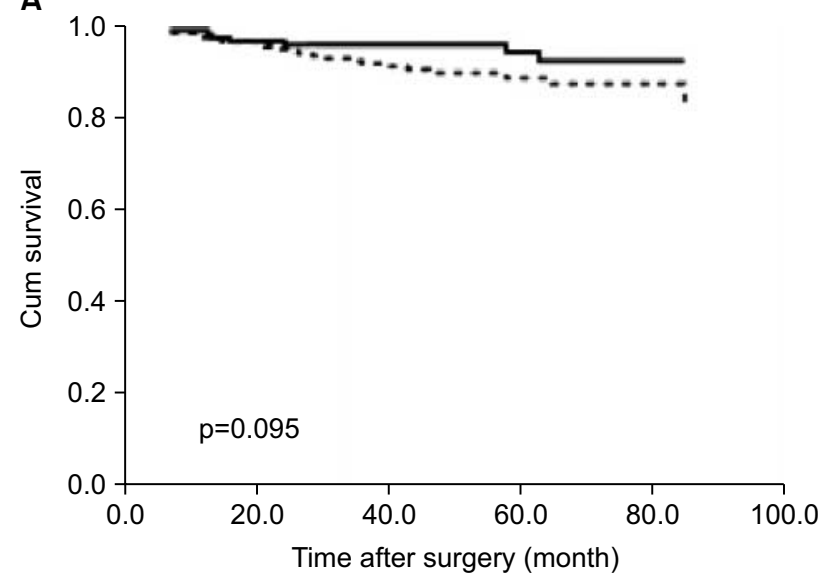

C

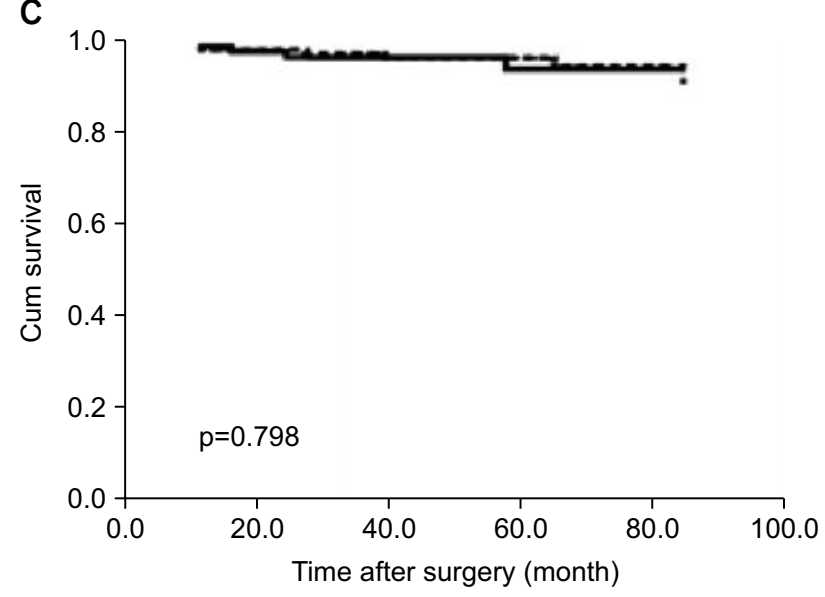

B

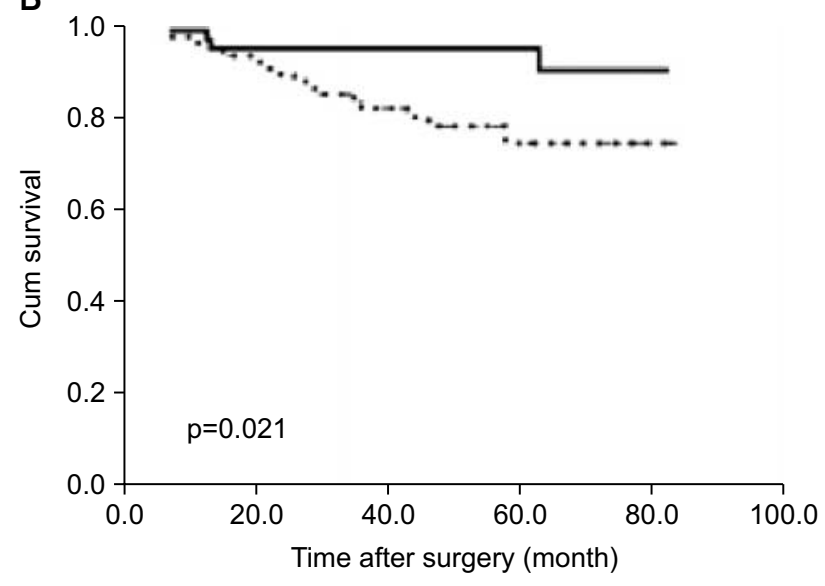

Fig. 2. Overall survival according to a leptin expression in (A) all the patients and the subgroup analyses according to the hormone receptor status, (B) is negative hormone receptor and (C) is positive hormone receptor. The dotted line represents a negative leptin expression and the continuous line represents a positive leptin expression. 
Table 5. Kaplan-Meier analysis of leptin expression according to hormone receptor status for overall survival and relapse-free survival (RFS)

\begin{tabular}{|c|c|c|c|c|c|}
\hline Leptin & $\mathrm{N}$ & Overall survival (\%) & $\mathrm{p}$ & RFS (\%) & $\mathrm{p}$ \\
\hline \multicolumn{6}{|l|}{ All } \\
\hline Leptin-negative & 201 & 90.0 & 0.095 & 83.1 & 0.782 \\
\hline Leptin-positive & 135 & 95.6 & & 84.6 & \\
\hline \multicolumn{6}{|c|}{ Hormone receptor negative } \\
\hline Leptin-negative & 72 & 79.2 & 0.021 & 77.8 & 0.656 \\
\hline Leptin-positive & 53 & 94.3 & & 81.5 & \\
\hline \multicolumn{6}{|c|}{ Hormone receptor positive } \\
\hline Leptin-negative & 129 & 96.1 & 0.798 & 86.0 & 0.967 \\
\hline Leptin-positive & 82 & 96.3 & & 86.6 & \\
\hline
\end{tabular}

Table 6. Multivariate analysis of prognostic factors for overall survival and relapse-free survival (RFS)

\begin{tabular}{|c|c|c|c|c|c|c|}
\hline & \multicolumn{3}{|c|}{ Overall survival } & \multicolumn{3}{|c|}{ RFS } \\
\hline & HR & $95 \% \mathrm{CI}$ & $\mathrm{p}$ & $\mathrm{HR}$ & $95 \% \mathrm{CI}$ & $\mathrm{p}$ \\
\hline \multicolumn{7}{|l|}{ Model with hormone receptor } \\
\hline Tumor size, $>2 \mathrm{~cm}$ & 3.95 & 1.03 to 15.16 & 0.05 & 1.26 & 0.60 to 2.66 & 0.54 \\
\hline Lymph node positive & 3.57 & 1.01 to 12.62 & 0.05 & 2.34 & 1.11 to 4.92 & 0.03 \\
\hline Hormone receptor positive & 0.04 & 0.01 to 0.34 & 0.00 & 0.57 & 0.28 to 1.20 & 0.14 \\
\hline Leptin positive & 0.26 & 0.06 to 1.21 & 0.09 & 1.03 & 0.49 to 2.17 & 0.93 \\
\hline Ob-R positive & 1.21 & 0.25 to 5.75 & 0.81 & 1.20 & 0.49 to 2.96 & 0.69 \\
\hline \multicolumn{7}{|c|}{ Model with chemotherapy and hormone therapy } \\
\hline Tumor size, $>2 \mathrm{~cm}$ & 5.63 & 1.35 to 23.48 & 0.02 & 1.19 & 0.55 to 2.55 & 0.66 \\
\hline Lymph node positive & 3.42 & 0.88 to 13.33 & 0.08 & 1.89 & 0.88 to 4.09 & 0.10 \\
\hline Hormone receptor positive & 0.02 & 0.00 to 0.16 & 0.00 & 0.41 & 0.17 to 0.98 & 0.05 \\
\hline Leptin positive & 0.20 & 0.04 to 0.99 & 0.05 & 0.98 & 0.46 to 2.06 & 0.95 \\
\hline Ob-R positive & 1.87 & 0.36 to 9.80 & 0.46 & 1.17 & 0.47 to 2.88 & 0.74 \\
\hline Chemotherapy, yes & 0.79 & 0.07 to 8.58 & 0.85 & 1.97 & 0.54 to 7.25 & 0.31 \\
\hline Hormone therapy, yes & 4.38 & 1.11 to 17.24 & 0.03 & 2.16 & 0.78 to 6.00 & 0.14 \\
\hline
\end{tabular}

Table 7. Kaplan-Meier survival analysis for adjuvant therapy in leptin-positive and leptin-negative breast cancer

\begin{tabular}{|c|c|c|c|c|c|c|c|c|c|c|}
\hline \multirow{2}{*}{ Adjuvant therapy } & & \multicolumn{3}{|c|}{ Total } & \multicolumn{3}{|c|}{ Leptin-negative } & \multicolumn{3}{|c|}{ Leptin-positive } \\
\hline & & $\mathrm{N}$ & $\%$ & $\mathrm{p}$ & $\mathrm{N}$ & $\%$ & $\mathrm{p}$ & $\mathrm{N}$ & $\%$ & $\mathrm{p}$ \\
\hline \multicolumn{11}{|l|}{ Overall survival } \\
\hline \multirow[t]{2}{*}{ Chemotherapy } & No & 82 & 98.8 & 0.03 & 47 & 97.9 & 0.06 & 29 & 100.0 & 0.23 \\
\hline & Yes & 269 & 90.7 & & 154 & 87.7 & & 106 & 94.3 & \\
\hline \multirow[t]{2}{*}{ Hormone therapy } & No & 98 & 88.8 & 0.51 & 59 & 84.7 & 0.07 & 35 & 94.3 & 0.59 \\
\hline & Yes & 253 & 94.1 & & 142 & 92.3 & & 100 & 96.0 & \\
\hline \multicolumn{11}{|l|}{ RFS } \\
\hline \multirow[t]{2}{*}{ Chemotherapy } & No & 82 & 96.3 & 0.01 & 47 & 97.9 & 0.00 & 29 & 93.1 & 0.20 \\
\hline & Yes & 270 & 80.4 & & 154 & 78.6 & & 107 & 82.2 & \\
\hline \multirow[t]{2}{*}{ Hormone therapy } & No & 99 & 82.8 & 0.53 & 59 & 83.1 & 0.84 & 36 & 83.3 & 0.67 \\
\hline & Yes & 253 & 84.6 & & 142 & 83.1 & & 100 & 85.0 & \\
\hline
\end{tabular}

node status and the hormone receptor status were significant independent factors that affected overall survival; the lymph node status was a significant independent factor affecting RFS in a model with variables that included the tumor size, the lymph node status, the hormone receptor status, a leptin expression and a Ob-R expression (Table 6). In a second model with variables that included 
chemotherapy and hormone therapy, the patients with leptinpositive breast cancer had a hazard ratio for overall survival of 0.20 ( $95 \%$ CI, 0.04 to $0.99 ; \mathrm{p}=0.05$ ).

\section{Benefit of chemotherapy for the leptin-positive group}

The correlation of the benefit of adjuvant therapy and a leptin expression was studied by performing Kaplan-Meier analysis on the leptin-positive and leptin-negative groups (Table 7). The leptinpositive group patients showed a significant benefit from chemotherapy for RFS as compared to that of the leptin-negative group. However, no significant difference was noted between the leptin-negative and leptin-positive groups for hormone therapy.

\section{Discussion}

In our study of the immunohistochemical expression of the leptin/Ob-R system and the breast cancer-related prognostic variables, we observed a significant correlation between a leptin expression and the Ki-67 labeling index in breast cancers. There are previous in vitro studies that have demonstrated that leptin stimulates the proliferation of cancer cells (12), it inhibits apoptosis (13) and it induces angiogenesis (14). Leptin was recently reported to stimulate the proliferation of various types of tumor cells (prostate, colorectal and lung) (15). Similar results have been described for breast cancer; leptin has been shown to stimulate the proliferation of breast cancer cell lines (16). These mitogenic effects are directly related to the activation of the extracellular signalregulated kinase (ERK) and Akt signaling pathways, which are both involved in breast cancer cell proliferation. To date, the prevailing hypothesis has been that the effects of leptin are primarily mediated through the action of ERK signaling pathway. However, it has been suggested that leptin may stimulate the ER-negative breast cancer cells by altering the mitogenic signaling pathways to promote the pathogenesis of cancer (17).

There are some reports regarding the correlation between the prognosis of breast cancers and the leptin expression and the Ob-R expression in breast cancer tissues (5,18-20). Miyoshi et al. (21) reported that a high expression of Ob-R mRNA in breast cancer tissue predicts a poor prognosis for the patients with high leptin levels in their sera. Revillion et al. (18) reported that an elevated messenger RNA expression of the short isoform of leptin receptor (OB-R-S) was associated with a shorter RFS.

In contrast, our results showed that the expression of leptin correlates with a better overall survival for patients with hormone receptor-negative breast cancers, but not for patients with hormone receptor-positive breast cancers. Our results showed that the leptinpositive breast cancer patients obtained significant benefit from chemotherapy for the RFS.
For colorectal adenocarcinoma, it has been reported that a leptin expression correlates with a favorable clinicopathologic phenotype and a better prognosis (22). Our results showed that patients with leptin-positive breast cancer and who received chemotherapy had a survival benefit. It is possible that a leptin expression might positively influence the sensitivity to chemotherapy or radiotherapy during postoperative adjuvant treatment.

Limited studies on cancer and non-cancer breast biopsies have indicated that both leptin and Ob-R are present in human breast tissue, and this suggests that the mammary gland is influenced by leptin, not only through paracrine or endocrine mechanisms, but also via the autocrine pathways (4). Chen et al. (23) reported there was no significant effect of the surgical removal of tumors on the high serum leptin concentrations in breast cancer patients. This finding is consistent with the idea that production of leptin by tumor is a minor source of the adipokine, while the unexcised adipose tissue remains a major contributor to the circulating leptin levels (17). Thus, a leptin expression in breast cancer tissue is considered to be a product of the paracrine pathway for the serum leptin that's produced in peritumoral adipose tissue with its release into the circulation. The paracrine relationship between the breast cancer cells and the surrounding breast adipose tissue appears to be more important in terms of bioregulatory effects than is a potential leptin-mediated autocrine loop (17). There are some controversial reports concerned with the plasma and serum leptin concentrations and the risk of breast cancer $(23,24)$, and so further studies on the circulating leptin concentrations in relation to the leptin expression in breast cancer tissue and the breast cancer risk are needed.

The completion of a paracrine loop requires the presence of a specific ligand-binding receptor on the target cell. The Ob-R occurs in multiple forms, and only one of these (the long form [LRb or OB$\mathrm{RI}]$ ) has an intracellular domain of sufficient length to provide for full signal-transducing capabilities (17). In this study, we used the antibody against $\mathrm{Ob}-\mathrm{R}$, which detects the short and long forms of $\mathrm{Ob}-\mathrm{R}$ of mouse, rat and human origins.

\section{Conclusion}

The leptin expression and the Ob-R expression were closely associated with breast tumorigenesis. A leptin expression was significantly related to a high Ki-67 labeling index, and this suggests an important role for leptin in breast carcinogenesis. For the hormone receptor-negative breast cancers, a leptin expression in breast cancers was inversely correlated with the prognosis. These findings suggest that leptin may be an important prognostic marker for breast cancer in the hormone receptor-negative patients. Further studies are needed to understand the exact role of a leptin expression in breast cancer. 


\section{References}

1. Reinier KS, Vacek PM, Geller BM. Risk factors for breast carcinoma in situ versus invasive breast cancer in a prospective study of pre- and post-menopausal women. Breast Cancer Res Treat. 2007;103:343-8.

2. Calle EE, Thun MJ. Obesity and cancer. Oncogene. 2004;23:6365-78.

3. Garofalo C, Surmacz E. Leptin and cancer. J Cell Physiol. 2006;207:12-22.

4. Garofalo C, Koda M, Cascio S, Sulkowska M, Kanczuga-Koda L, Golaszewska J, et al. Increased expression of leptin and the leptin receptor as a marker of breast cancer progression: possible role of obesity-related stimuli. Clin Cancer Res. 2006;12:1447-53.

5. Ishikawa M, Kitayama J, Nagawa H. Enhanced expression of leptin and leptin receptor (OB-R) in human breast cancer. Clin Cancer Res. 2004;10:4325-31.

6. Saxena NK, Sharma D, Ding X, Lin S, Marra F, Merlin D, et al. Concomitant activation of the JAK/STAT, PI3K/AKT, and ERK signaling is involved in leptin-mediated promotion of invasion and migration of hepatocellular carcinoma cells. Cancer Res. 2007:67:2497-507.

7. Rose DP, Gilhooly EM, Nixon DW. Adverse effects of obesity on breast cancer prognosis, and the biological actions of leptin (review). Int J Oncol. 2002;21:1285-92.

8. Bahrenberg G, Behrmann I, Barthel A, Hekerman P, Heinrich PC, Joost HG, et al. Identification of the critical sequence elements in the cytoplasmic domain of leptin receptor isoforms required for Janus kinase/signal transducer and activator of transcription activation by receptor heterodimers. Mol Endocrinol. 2002;16:859-72.

9. Bjorbaek C, Uotani S, da Silva B, Flier JS. Divergent signaling capacities of the long and short isoforms of the leptin receptor. J Biol Chem. 1997;272:32686-95.

10. Yin $N$, Wang D, Zhang $H, Y i X$, Sun $X$, Shi B, et al. Molecular mechanisms involved in the growth stimulation of breast cancer cells by leptin. Cancer Res. 2004;64:5870-5

11. Greene FL, Page DL, Fleming ID, Fritz AG, Balch CM, Haller DG, et al. AJCC cancer staging manual. Part VII Breast. 6th ed. 2002. p.221-40.

12. Onuma M, Bub JD, Rummel TL, Iwamoto Y. Prostate cancer cell-adipocyte interaction: leptin mediates androgen-independent prostate cancer cell proliferation through c-Jun NH2-terminal kinase. J Biol Chem. 2003;278:42660-7.

13. Rouet-Benzineb P, Aparicio T, Guilmeau S, Pouzet C, Descatoire V, Buyse M, et al.
Leptin counteracts sodium butyrate-induced apoptosis in human colon cancer HT-29 cells via NF-kappaB signaling. J Biol Chem. 2004;279:16495-502.

14. Bouloumie A, Drexler HC, Lafontan M, Busse R. Leptin, the product of Ob gene, promotes angiogenesis. Circ Res. 1998;83:1059-66.

15. Tessitore L, Vizio B, Jenkins O, De Stefano I, Ritossa C, Argiles JM, et al. Leptin expression in colorectal and breast cancer patients. Int J Mol Med. 2000;5:421-6.

16. Hu X, Juneja SC, Maihle NJ, Cleary MP. Leptin--a growth factor in normal and malignant breast cells and for normal mammary gland development. J Natl Cancer Inst. 2002:94:1704-11.

17. Vona-Davis L, Rose DP. Adipokines as endocrine, paracrine, and autocrine factors in breast cancer risk and progression. Endocr Relat Cancer. 2007;14:189-206.

18. Revillion F, Charlier M, Lhotellier V, Hornez L, Giard S, Baranzelli MC, et al. Messenger RNA expression of leptin and leptin receptors and their prognostic value in 322 human primary breast cancers. Clin Cancer Res. 2006;12(7 Pt 1):2088-94.

19. Jarde T, Caldefie-Chezet F, Damez M, Mishellany F, Penault-Llorca F, Guillot J, et al. Leptin and leptin receptor involvement in cancer development: a study on human primary breast carcinoma. Oncol Rep. 2008;19:905-11.

20. Caldefie-Chezet F, Damez M, de Latour M, Konska G, Mishellani F, Fusillier C, et al Leptin: a proliferative factor for breast cancer? Study on human ductal carcinoma. Biochem Biophys Res Commun. 2005;334:737-41.

21. Miyoshi Y, Funahashi T, Tanaka S, Taguchi T, Tamaki Y, Shimomura I, et al. High expression of leptin receptor mRNA in breast cancer tissue predicts poor prognosis for patients with high, but not low, serum leptin levels. Int J Cancer. 2006;118:1414-9.

22. Paik SS, Jang SM, Jang KS, Lee KH, Choi D, Jang SJ. Leptin expression correlates with favorable clinicopathologic phenotype and better prognosis in colorectal adenocarcinoma. Ann Surg Oncol. 2009;16:297-303.

23. Chen DC, Chung YF, Yeh YT, Chaung HC, Kuo FC, Fu OY, et al. Serum adiponectin and leptin levels in Taiwanese breast cancer patients. Cancer Lett. 2006;237:109-14.

24. Woo HY, Park H, Ki CS, Park YL, Bae WG. Relationships among serum leptin, leptin receptor gene polymorphisms, and breast cancer in Korea. Cancer Lett. 2006;237:137-42. 